\title{
El Tribunal Administrativo Central de Recursos Contractuales
}

\author{
Juan José Pardo García-Valdecasas \\ Presidente Tribunal Administrativo Central de Recursos Contractuales \\ juanjose.pardo@minhap.es
}

\begin{abstract}
Resumen
La publicación de la Directiva 2007/66/CE, de 11 de diciembre, del Consejo y el Parlamento Europeo por la que se modificaba la 1989/665/CEE, de 21 de diciembre, tuvo como objetivo el reforzamiento de la eficacia del sistema de recursos en materia de contratación pública. Este reforzamiento se ha traducido entre otras cosas en la suspensión del expediente de adjudicación hasta que se resuelva por el órgano competente sobre el fondo o sobre la conveniencia o no de mantener suspendido el procedimiento. Con estas modificaciones el sistema de recursos español requería o bien de la modificación del procedimiento contencioso administrativo, al menos en lo referente a la suspensión del acto recurrido, o la creación de un órgano especializado que ejerciera la competencia para resolver estos recursos. Las peculiaridades del procedimiento contencioso administrativo y la especial carga de trabajo que recae sobre los tribunales de este orden jurisdiccional, aconsejaron al legislador español hacer uso de la posibilidad contenida en la Directiva 89/665/CEE de encomendar la competencia a un órgano administrativo independiente. Este es el origen del Tribunal Administrativo Central de Recursos Contractuales y de los órganos equivalentes creados por las Comunidades Autónomas. Su regulación debe contemplar como requisito esencial el de eficacia lo cual comporta, además de su independencia, la necesidad de establecer unas pautas de resolución inexcusablemente breves. Sólo de esta forma es posible conjugar la necesidad de dar satisfacción a las pretensiones de los recurrentes cuyos recursos se estimen con la de no incidir de forma negativa en la contratación pública dilatando más allá de lo prudente la suspensión del procedimiento contractual. El artículo que sigue sobre la materia trata de dar respuesta a las preguntas que derivan de los planteamientos anteriores.
\end{abstract}

Palabras clave Administración General del Estado, Contratación Pública, Adjudicación, Recurso especial.

\section{The Public Procurement Review Central Administrative Court}

\begin{abstract}
The publication of Directive 2007/66/EC, of 11 December, of the European Parliament and of the Council, amending Directive 1989/665/EEC, of 21 December, was aimed at improving the effectiveness of the review system concerning the award of public contracts. This improvement has, among other things, given rise to the suspension of the contract award procedure until the competent authority has adopted a decision on the issue in question or on the appropriateness of maintaining the procedure suspended. With these changes the Spanish review system needed to either modify the contentious-administrative procedure, at least with regard to the suspension of the contested act, or set up a specialised body with jurisdiction to resolve these reviews. The peculiarities of the contentious-administrative procedure and the considerable workload of the courts in this jurisdiction pushed the Spanish legislator to make use of the possibility contained in Directive 89/665/EEC to confer the review procedure on an independent administrative body. This marked the birth of the Public Procurement Review Central Administrative Court and the equivalent bodies set up in the autonomous regions. Their regulatory system should place emphasis on the essential requirement of effectiveness, which, apart from independence, includes the need to establish necessarily brief resolution guidelines. This is the only possible way to balance the need to recognise the claims of appellants whose reviews are upheld with the need to avoid the negative impact on public procurement of prolonging the suspension of the public procurement procedure longer than is reasonable. The article that follows seeks to answer the questions that derive from the issues raised above.
\end{abstract}

Key words

Central State Administration, Public procurement, Award, Special review. 


\section{INTRODUCCIÓN}

\section{Definición}

El objetivo que pretende este artículo, no es otro que presentar una visión panorámica acerca de la estructura y funciones del Tribunal Administrativo Central de Recursos Contractuales, enfocada principalmente a exponer cuáles son sus características y en qué medida éstas justifican la creación de un nuevo órgano con funciones, que bien podrían englobarse en el conjunto de las que ya tienen atribuidas otros órganos de la Administración, por no mencionar a la Jurisdicción contencioso administrativa.

Puede considerarse contradictorio que, cuando todas las voces en el ámbito de las administraciones públicas, claman por la simplificación y la supresión de aquellos organismos que resultan redundantes, atendido el ámbito de competencia que tienen o pueden tener atribuida, el legislador decidiera con la aprobación de la Ley $34 / 2010$, de 5 de agosto introducir un nuevo recurso con aplicación estrictamente a la materia contractual y un nuevo órgano destinado exclusivamente a resolverlo. Desde cualquier punto de vista, es claro que ninguna de las dos decisiones coopera a la difícil política de simplificación, que tanto en el ámbito de la organización administrativa como en el aún más proceloso de sus trámites se pretende alcanzar, con escaso éxito, desde hace ya un buen número de años.

Sin embargo, las circunstancias mandan y, aunque el legislador se lo proponga y trate de ser coherente con los planteamientos simplificadores aludidos, no siempre es posible conseguirlo.

Este es, según veremos, el caso del Tribunal Administrativo Central de Recursos Contractuales, y de la secuela de tribunales análogos que van surgiendo en las Comunidades Autónomas. Han venido a constituir una clara contradicción con las pretensiones simplificadoras que imperan en la doctrina y en la práctica.

Dejamos para más adelante el hacer un examen algo más extenso de esta cuestión para, en este primer momento, tratar de aportar una definición del mismo que desde el punto de vista doctrinal permita en la medida de lo posible, tener una idea clara acerca de qué es este Tribunal.

"Como decimos, el Tribunal Administrativo Central de Recursos Contractuales ha sido creado por la Ley 34/2010, de 5 de agosto por la que se reforman las leyes 30 y 31 de 2007, reguladoras de la contratación pública en sentido amplio así como la Ley reguladora de la Jurisdicción contencioso administrativa, en lo referente a la impugnación de las resoluciones dictadas en los recursos de que conozca. Por ello, se incorporan a la Ley 30/2007, de 30 de abril, de contratos del sector público, los artículos 310 a 320, ambos inclusive, que pasaron a constituir un nuevo Libro, el sexto de la

20 misma, y tienen como objeto regular el recurso especial en materia de contratación y 
los órganos encargados de resolverlo en el ámbito de las diferentes administraciones territoriales. Una vez aprobado el Texto Refundido de la Ley de Contratos del Sector Público, mediante Real Decreto Legislativo 3/2011, de 14 de noviembre, la regulación se ha ubicado dentro del Libro I de la Ley, ocupando los artículos 40 a 50 de la misma.

Idéntica labor realizan los nuevos artículos 101 a 108 de la Ley 31/2007, de 30 de octubre, sobre procedimientos de adjudicación en los sectores denominados especiales".

En base a los citados preceptos, el Tribunal Administrativo Central de recursos contractuales puede considerarse como el órgano administrativo que tiene encomendada la competencia para resolver los recursos especiales en materia de contratación.

Son, pues, diversas las características que definen este Tribunal.

En primer lugar es un órgano, no un organismo, lo que pone de manifiesto ya desde el principio, una idea importante a la hora de caracterizarlo: carece de personalidad jurídica propia integrándose en la estructura de la Administración del Estado como un órgano más. La Ley no menciona de modo expreso esta característica, pero de modo indirecto se refiere a ella cuando dice en su artículo 41.1 que "en el ámbito de la Administración General del Estado, el conocimiento y resolución de los recursos a que se refiere el artículo anterior estará encomendado a un órgano especializado". La Ley, pues, emplea para caracterizarlo también el término "órgano", que en la terminología del legislador no puede ser interpretado más que en el sentido de que carece de personalidad jurídica propia.

Por otra parte, para poder interpretar en sentido contrario la redacción de la Ley, habría sido necesario que ésta dejara claro, directa o indirectamente, que el Tribunal está dotado de personalidad jurídica independiente de la de la Administración a que se adscribe. En este ámbito, debe considerarse norma general que la personalidad jurídica no se presume. Ello quiere decir que si la norma de que se trate no deja clara la voluntad del legislador de crear un organismo, es decir de atribuirle personalidad jurídica propia, debe entenderse que no lo ha hecho.

Menos tajante en este sentido resulta la Ley cuando dispone que "a estos efectos se crea el Tribunal Administrativo Central de Recursos Contractuales que estará adscrito al Ministerio de Economía y Hacienda", pues el término adscrito puede utilizarse para especificar el vínculo con la Administración General del Estado, tanto en un caso como en el otro. A este respecto, incluso cabría considerar que el término mencionado podría resultar incluso contradictorio con la afirmación inicial de que el Tribunal no tiene personalidad jurídica propia, pues en tal caso, más que la adscripción al Ministerio de Economía y Hacienda, debería haberse establecido su integración en él. La mera adscripción, en efecto, resulta más apropiada para los organismos que gozan de autonomía en la gestión. 
Sin embargo, no debe hacerse excesivo hincapié en este punto, pues la utilización del término "adscrito" en lugar de "integrado", sin duda responde a la intención del legislador de poner de manifiesto, ya desde este plano, la plena independencia de actuación que debe tener el Tribunal.

Conviene aquí traer a colación la afirmación de algún autor, en el sentido de que adscribir el Tribunal al Ministerio de Economía y Hacienda a través de la Subsecretaría, puede ser una decisión del legislador contraria a la pretensión de independencia. Sin embargo, a nuestro juicio, la independencia queda suficientemente establecida, según veremos más adelante, por la afirmación hecha por el propio artículo 40, apartado 1, al decir que el Tribunal actuará con plena independencia funcional en el ejercicio de sus competencias. La adscripción del Tribunal al Ministerio de Economía y Hacienda es una consecuencia lógica derivada de su condición de órgano administrativo a que a continuación nos vamos a referir, pero en absoluto puede entenderse que es contradictoria con su independencia en el ejercicio de sus funciones.

El propio Consejo de Estado entendió en su Dictamen sobre el anteproyecto de ley creadora del Tribunal "que difícilmente cabe pensar, al menos dentro del esquema de personificaciones instrumentales que ofrece la Ley 6/1997, de 14 de abril, de Organización y Funcionamiento de la Administración General del Estado, en una modalidad que pueda ser aplicable para la configuración del mencionado órgano independiente".

En segundo lugar, es evidente que nos encontramos ante un órgano administrativo y no jurisdiccional. En efecto, a pesar de que por razón de la competencia que tiene atribuida, el Tribunal podría haber sido integrado en la estructura del poder judicial como un órgano más del mismo, lo cierto es que ésta no ha sido la opción de nuestro legislador. Por el contrario, ha optado por dotarlo de naturaleza administrativa haciendo uso de la facultad que al respecto le otorga la Directiva 89/665/CEE, en la redacción resultante de la modificación introducida por la Directiva 2007/66/CE, de 11 de diciembre de 2007. Ésta, en su artículo 2, apartado 9, admite expresamente la posibilidad de que el órgano que resuelva los recursos no tenga carácter jurisdiccional, de lo que sólo cabe deducir que admite la posibilidad de que se trate de un órgano administrativo. Ello conlleva, sin embargo, una serie de requisitos en la composición de dichos órganos y en el carácter de sus funciones, que no tienen otra finalidad que la de asimilarlos lo más posible a los órganos jurisdiccionales. En tal sentido se exige que las resoluciones se dicten por escrito, motivadamente y que sean susceptibles de impugnación ante un órgano jurisdiccional. Por otra parte, se exige la condición de independencia que se pretende garantizar, según más adelante vamos a ver, mediante la designación de los miembros del órgano en cuestión utilizando un procedimiento similar al previsto legalmente para la designación de los jueces y exigiendo el cumplimiento de requisitos profesionales semejantes.

Siendo evidente que el Tribunal se configura con el carácter de órgano administrativo, cabe, no obstante, plantearse la cuestión de si las características del ejercicio de su 22 función, unidas al hecho de que la elección de sus miembros se asimile a la de los jueces, 
no sería suficiente para caracterizarlo como un verdadero órgano jurisdiccional. La respuesta desde un principio debe ser negativa, habida cuenta de que no se integra en la estructura del Poder Judicial. Sin embargo, sí cabe plantearse si las circunstancias mencionadas, no lo asimilan a los órganos de la Administración de Justicia, de forma que deba ser considerado como un órgano de naturaleza cuasi jurisdiccional.

Analizando las características extrínsecas de la regulación que la Ley ha hecho del Tribunal, no hay duda de que, en principio, puede atribuírsele la condición expresada. A este respecto resulta interesante el contenido de la Sentencia del Tribunal de Justicia de las Comunidades Europeas dictada en el asunto C-110/98, con fecha 21 de marzo de 2000, en la que se atribuye la condición de cuasi jurisdiccionales a los Tribunales Económico Administrativos. Señala la mencionada resolución que para apreciar si un organismo "posee el carácter de un órgano jurisdiccional en el sentido del artículo 177 del Tratado, cuestión que pertenece únicamente al ámbito del Derecho comunitario, el Tribunal de Justicia tiene en cuenta un conjunto de elementos, como son el origen legal del órgano, su permanencia, el carácter obligatorio de su jurisdicción, el carácter contradictorio del procedimiento, la aplicación por parte del órgano de normas jurídicas, así como su independencia".

De las características indicadas, es evidente que el Tribunal Administrativo Central de recursos contractuales, reúne todas ellas a excepción del carácter obligatorio de su jurisdicción, puesto que a tenor del artículo 40.6 de la ley de Contratos del Sector Público: "El recurso especial regulado en este artículo y los siguientes tendrá carácter potestativo".

La ausencia de esta nota evidentemente lo priva de la condición de órgano jurisdiccional a la luz del derecho comunitario y a la del propio derecho interno español, pero no es suficiente para negarle la condición de órgano cuasi jurisdiccional habida cuenta de que el resto de las condiciones exigidas se cumplen.

La última nota que debe servirnos para establecer la definitiva calificación jurídica del Tribunal, es la de la independencia. Ésta aparece expresamente mencionada en el artículo 41.1 de la Ley de Contratos del Sector Público, según hemos visto anteriormente, y queda materializada de modo práctico en la regulación, que más adelante examinaremos, del modo en que sus miembros deben designarse, de los requisitos que deben reunir para ello y del carácter inamovible de sus cargos.

Igualmente, esta condición se desprende de la regulación que el artículo 47 de la Ley citada, de conformidad con el cual: "Contra la resolución dictada en este procedimiento sólo cabrá la interposición de recurso contencioso-administrativo conforme a lo dispuesto en el artículo 10, letras k) y l) del apartado 1 y en el artículo 11, letra f) de su apartado 1 de la Ley 29/1998, de 13 de julio, Reguladora de la Jurisdicción ContenciosoAdministrativa. No procederá la revisión de oficio regulada en el artículo 34 de esta Ley y en el Capítulo I del Título VII de la Ley 30/1992, de 26 de noviembre, de la resolución ni de ninguno de los actos dictados por los órganos regulados en el artículo 41. Tampoco 
estarán sujetos a fiscalización por los órganos de control financiero de las Administraciones a que cada uno de ellos se encuentre adscrito".

El texto del precepto transcrito pone de manifiesto que los actos resolutorios de los recursos que adopte el Tribunal, no podrán se revocados en ningún caso más que mediante una resolución de carácter judicial. Por el contrario, ningún órgano de naturaleza administrativa, cualquiera que sea su nivel jerárquico, estará facultado para revocar los citados actos.

Conviene entrar en el análisis un poco más detenido de cuáles son las notas que definen como independiente a un órgano y comprobar si las mismas concurren en el Tribunal Administrativo Central de recursos contractuales.

En primer lugar, debe decirse que la independencia del órgano se pone de manifiesto de manera primordial en el momento de dictar la resolución. Sin embargo, no debe reducirse a éste el momento en que la independencia debe jugar su papel. Por el contrario, la independencia lo juega en todos los momentos del procedimiento, para que el órgano en cuestión pueda, a través de los diferentes trámites de ésta, adquirir los elementos de juicio necesarios para dictar la resolución que proceda. No se podrá hablar de independencia, por tanto, si el Tribunal no puede acceder al conocimiento de todos aquellos elementos de juicio que le permitan dictar la resolución en los términos que mejor se ajusten a la correcta aplicación de la norma. En consecuencia, su carácter independiente debe ponerse de manifiesto también para practicar las pruebas, para poder oír a todas las partes comparecidas en el procedimiento y para recabar la aportación de todos los componentes del expediente administrativo que le deban servir de base a él y a las partes para formular adecuadamente su juicio sobre el fondo del asunto.

La doctrina, generalmente, ha señalado tres notas que pueden considerarse trascendentales para calificar un determinado órgano como independiente. Tales son, la ausencia de control por otros órganos pertenecientes a su propia estructura, por los órganos de carácter político y, finalmente, por las partes en el procedimiento.

Con respecto de los restantes órganos integrados en su misma estructura, la independencia implica, fundamentalmente, que éstos no puedan condicionar el sentido de las decisiones que el órgano deba adoptar. Este condicionamiento puede venir tanto de la imposición del sentido de la resolución que adopte el órgano, como de la adopción de medidas disciplinarias contra él si la resolución no tiene un determinado sentido. Hay que entender, sin embargo, que esta necesaria ausencia de control no es contraria a la posibilidad de que los órganos integrados en la misma estructura que tengan el carácter de superiores, puedan revocar las decisiones de los inferiores en uso del derecho de recurso ejercitado por los interesados.

La independencia respecto de las partes se traduce en imparcialidad, es decir 24 carencia de vinculación, cualquiera que sea el origen (familia, amistad, negocios...) 
con alguna de las partes. Tratándose de órganos administrativos esta es cuestión esencialmente relevante, dando lugar a las causas de abstención y recusación cuya inobservancia motivan la nulidad de la resolución.

Desde el punto de vista de la ausencia de control respecto del poder político, ha de tenerse en cuenta lo relativo a su nombramiento, desempeño de la función y remoción. El nombramiento debe hacerse sobre la base de criterios para la selección de carácter absolutamente objetivo, durante el ejercicio del mandato los miembros del órgano administrativo no pueden ser trasladados de su puesto de trabajo más que a petición propia y, finalmente, el cese sólo puede acordarse en virtud de las causas legalmente previstas y previa la tramitación de un procedimiento dotado de las adecuadas garantías.

Sólo en aquellos casos en que el órgano administrativo reúna estos requisitos puede hablarse de independencia. Es decir, sólo cabe hablar de ella en los casos en que se den las prerrogativas y garantías que presiden el ejercicio de la función jurisdiccional.

Dicho esto, queda claro que la independencia del órgano al que se encomiende la resolución de los recursos, es requisito esencial de la eficacia de éstos. De lo contrario, el recurso se convierte en un mero trámite de confirmación del acto que se impugna y lejos de constituir una garantía para la objetividad del procedimiento, se convierte en un obstáculo a su culminación.

Pero no deben reducirse a la independencia los requisitos que un órgano debe reunir para que el procedimiento de recurso deba considerarse eficaz a los efectos que motivan su creación. Por el contrario, para ello es preciso que además el órgano esté concebido de forma que puede hacer efectiva la exigencia de celeridad en la adopción de las resoluciones. De nada sirve crear un órgano, administrativo o jurisdiccional, con todas las competencias imaginables en cuanto a la resolución del procedimiento, si no se le dota de los medios personales precisos para garantizar la posibilidad de que adopte sus decisiones en el tiempo más breve posible.

El gran problema de la regulación de los recursos en materia de contratación, se encuentra precisamente en que si la resolución es adoptada tardíamente, el restablecimiento pleno de la legalidad no se puede alcanzar nunca a través de ella, pues la adjudicación y, frecuentemente, también la ejecución del contrato, se habrán producido con anterioridad a que se dicte aquélla. En efecto, en tales casos el recurrente que obtenga una resolución favorable, no podrá conseguir a través de ella lo que, indudablemente, es el fundamento de su reclamación: obtener la adjudicación del contrato y ejecutarlo. Es cierto que siempre cabe la posibilidad de acordar la correspondiente compensación económica, pero ésta no es sino una solución alternativa y, por supuesto, no constituye la plena satisfacción de lo pretendido. Puede pensarse que la empresa, a través de la licitación en que ve truncadas sus opciones de lograr la adjudicación del contrato, buscaba fundamentalmente la obtención de un beneficio y que éste es fácilmente compensable condenando a la Administración al pago del 
lucro cesante, más los intereses correspondientes. Sin embargo, quien mantenga un criterio así, desconoce el verdadero sentido de la contratación. Efectivamente, el empresario buscará de forma primordial la obtención de un beneficio a través de la ejecución del contrato, pero éste no es el único motivo por el que una empresa aspira a la adjudicación. No es este el momento ni el foro adecuado para hacer el análisis de las posibles motivaciones, de toda índole, que pueden mover al empresario a participar en la licitación de un contrato público, pero aún así baste con señalar como una motivación habitual en la contratación, la de poder adquirir datos objetivos de solvencia que le permitan optar, en licitaciones futuras, a la adjudicación de determinados contratos. Pues bien, este objetivo queda truncado si no se logra la adjudicación del contrato como consecuencia de una infracción legal cometida en el procedimiento de adjudicación por el órgano de contratación.

En consecuencia, aparece como uno de los requisitos esenciales que debe reunir el órgano administrativo encargado de resolver los recursos en materia de contratos públicos, la suficiencia de medios tanto materiales como personales. Este requisito lo es de la eficacia de su actuación, e indirectamente también de su independencia. Evidentemente, la independencia del órgano puede ser cercenada también, si el órgano administrativo del que depende la provisión de los medios necesarios para ejercer su función no lo hace. Esto es especialmente claro en aquéllos casos en que el organismo que debe proveer los medios pertenezca a la misma estructura administrativa que el órgano de recurso controla.

Esta dotación de medios no abarca exclusivamente los de carácter material, aunque obviamente éstos también tienen importancia, sino de modo muy especial la de medios personales. El órgano encargado de resolver los recursos deberá, así, estar estructurado de forma que su competencia se ejerza en el territorio sobre el que recae a través de órganos que la acerquen al ciudadano. Tales órganos deberán estar integrados por el número suficiente de miembros como para poder resolver los recursos en el tiempo que la eficacia exige, y, por último, deberá contar con la estructura de apoyo técnico y administrativo que esta misma requiera'.

\section{ANTECEDENTES}

El intento persistente de las autoridades surgidas del Tratado constitutivo de las Comunidades Europeas por dar cumplimiento a los principios consagrados por él, y en especial por lo que aquí nos interesa a la implantación de un mercado único europeo, ha llevado a la adopción de una serie casi interminable de normas jurídicas con la finalidad de crear condiciones de armonía entre los diferentes derechos internos de los Estados miembros.

26 de un libro que aún no ha visto la luz. 
El ámbito de la contratación pública no podía ser una excepción teniendo en cuenta su entidad desde los puntos de vista económico y financiero en relación con la actividad general del Estado en estas materias.

A base de ahondar en la exigencia de coordinación en los procedimientos para la selección de los contratistas, las normas comunitarias han ido abarcando cada vez más aspectos de la contratación pública. En estos intentos, se ha llegado incluso a la exigencia de introducir en la legislación interna de cada Estado miembro procedimientos de recurso que permitan a los interesados cuyos intereses legítimos hayan podido ser dañados por las decisiones adoptadas en tales procedimientos recurrir contra ellas y, en su caso, obtener su anulación antes de que se haya comenzado a ejecutar el contrato.

Con esto, los órganos de la Unión Europea no han hecho otra cosa que seguir avanzando por el cada vez más complejo sendero de la armonización de legislaciones incrementando e intensificando el profuso (y confuso probablemente) acervo normativo comunitario.

Esta etapa final en que ahora nos encontramos y que, no debe dudarse, en breve quedará obsoleta como consecuencia de la aprobación de nuevas normas que vendrán a complicarla aún más, es el resultado de una evolución que parte de una primitiva situación en que nuestro derecho no contaba con procedimientos específicos para resolver los recursos en el ámbito de la contratación pública y, menos aún, con órganos encargados exclusivamente de resolverlos.

En efecto, ni la Ley de Contratos del Estado de 8 de abril de 1965, primera norma que sistematiza la regulación de la contratación pública española, ni la Ley 13/1995, de 18 de mayo, de Contratos de las Administraciones Públicas como tampoco el texto refundido de esta última, de 16 de junio de 2000, contenían normas en relación con el recurso ni con los órganos que debieran encargarse de resolverlo.

La justificación de esta circunstancia en todas ellas debe hallarse en la convicción del legislador español de que el sistema de recursos establecido en nuestro derecho era suficiente para garantizar el cumplimiento de las exigencias del derecho comunitario en la materia.

En efecto, la regulación tradicional en nuestras leyes de procedimiento venía reconociendo a quienes fueran titulares de intereses legítimos o de derechos subjetivos, la facultad de recurrir contra los actos de cualquier procedimiento y, por tanto, también contra los del procedimiento de adjudicación de los contratos, incluidos los actos de trámite en determinadas circunstancias. Como consecuencia de ello, sin necesidad de declaración expresa, tanto la Ley de Contratos del Estado como la de Contratos de las Administraciones Públicas partían de la base de que tales actos eran recurribles de conformidad con las normas del procedimiento administrativo general. Lo mismo cabe decir de la legislación de régimen local. 
A este respecto, conviene recordar que la Ley 30/1992, de 26 de noviembre, de Régimen jurídico de las Administraciones públicas y del Procedimiento administrativo común dispone en su artículo 107, apartado 1, que "contra las resoluciones y los actos de trámite, si estos últimos deciden directa o indirectamente el fondo del asunto, determinan la imposibilidad de continuar el procedimiento, producen indefensión o perjuicio irreparable a derechos e intereses legítimos, podrán interponerse por los interesados los recursos de alzada y potestativo de reposición...". Puesto que el procedimiento de adjudicación de los contratos reúne las características de todo procedimiento administrativo en el que el acto adjudicando el contrato constituye el acto resolutorio del mismo, es evidente que tanto éste último como los de trámite que se encuentren incluidos en alguno de los supuestos mencionados en el artículo trascrito son susceptibles de ser objeto de un recurso de alzada o de reposición según proceda.

Por ello, se entiende que nuestro legislador al redactar la Ley de Contratos de las Administraciones Públicas entendiera que no existía necesidad de introducir normas específicas para regular el recurso en materia contractual pública, dado que el sistema jurídico español vigente permitía ejercitar las acciones de defensa pertinentes contra los actos de adjudicación y los del procedimiento que los precede.

Esta convicción resultaba reforzada por el hecho de que los actos dictados resolviendo los recursos por los órganos administrativos eran recurribles ante la Jurisdicción contencioso administrativa, lo que garantizaba la resolución final por un órgano independiente.

Este entramado normativo permitía entender que el sistema general de recursos, apreciado en su conjunto, satisfacía suficientemente las exigencias de la normativa comunitaria. Refiriéndonos de forma exclusiva a la Directiva de recursos 89/665/ CEE, actualmente en vigor, aunque notablemente reformada según veremos, ésta exigía en su artículo 1.1: “... los Estados miembros tomarán las medidas necesarias para garantizar que las decisiones adoptadas por las entidades adjudicadoras puedan ser recurridas de manera eficaz y, en particular, lo más rápidamente posible... ". El contenido de este precepto puede considerarse suficientemente recogido en el artículo 107 de la Ley 30/1992, de 26 de noviembre, que entes hemos citado.

Por otra parte, el artículo 2.3 de la misma Directiva establecía que "por símismos, los procedimientos de recurso no deberán tener necesariamente efectos suspensivos automáticos en los procedimientos de adjudicación de contratos públicos a los que se refiera". Precepto que resultaba plenamente conforme con el contenido del artículo 111 de la Ley antes citada, de conformidad con el cual "La interposición de cualquier recurso, excepto en los casos en que una disposición establezca lo contrario, no suspenderá la ejecución del acto impugnado".

Especialmente no mencionamos el requisito de la eficacia porque, tal como ya hemos tenido ocasión de exponer, la práctica ha puesto de manifiesto reiteradamen28 te la ineficacia de este sistema de recursos en relación con el pleno restablecimiento 
de la legalidad conculcada. Esto es evidente en relación con los casos en que la resolución del recurso fuera estimatoria de las pretensiones del recurrente, pues, por regla general, éste a lo más que podía aspirar era a la compensación de los perjuicios ocasionados por la infracción legal, representado básicamente por el lucro cesante derivado de la no aceptación de su oferta.

Y ello, porque el tiempo que, habitualmente, resulta necesario para resolver el recurso, especialmente si es preciso acudir a la jurisdicción contencioso administrativa, era tal que el obtener una resolución estimatoria del mismo en absoluto garantizaba la efectividad de la pretensión, normalmente consistente en obtener la adjudicación del contrato. La razón es bien sencilla: al dictar la resolución, el contrato generalmente no sólo estaba adjudicado sino incluso ejecutado. De esta forma, la única opción para poder ejecutar la resolución o la sentencia dictadas pasaba por el resarcimiento de los daños, pero nunca por la auténtica reposición del recurrente en su derecho. La violación de éste, en la práctica quedaba consumada.

Esta situación, evidentemente no era exclusiva de nuestro derecho, como se desprende del contenido de algunos de los exponendos de la Directiva 2007/66/CE, de 11 de diciembre de 2007. Así, según ella, "las consultas con las partes interesadas, así como la jurisprudencia del Tribunal de Justicia, han puesto de manifiesto una serie de puntos débiles en los mecanismos de recurso existentes en los Estados miembros. Esta es la razón por la que los mecanismos establecidos en las Directivas 89/665/CEE y 92/13/ CEE no siempre permiten velar por el cumplimiento de la legislación comunitaria, en particular en una etapa en la que aún podrían corregirse las infracciones. Así pues, las garantías de transparencia y no discriminación que se querían establecer mediante dichas Directivas deben reforzarse".

Es decir, la propia Comisión europea era consciente de que las Directivas hasta entonces en vigor, no habían servido a la finalidad que las había motivado, pues existían, según hemos visto, puntos débiles en los mecanismos de recursos que eran consecuencia de la propia configuración que del recurso habían hecho las citadas directivas.

Resulta especialmente relevante, poner de manifiesto que, junto a las consultas efectuadas a las partes, los órganos de la Unión Europea consideraban que diversos pronunciamientos del Tribunal de Justicia, exigían una reordenación de la materia con objeto de establecer una elemental sistematización de la misma. Tales sentencias eran fundamentalmente las siguientes:

Primeramente la dictada en el asunto C-81/98 (Alcatel-Austria) de la que derivó la obligación para los Estados miembros de establecer un procedimiento de recurso, que permita al demandante obtener con anterioridad a la celebración de contrato y si concurren los correspondientes requisitos, la anulación de la decisión del órgano de contratación por la que resuelve con qué licitador celebrará el contrato. 
En segundo lugar, la Sentencia del asunto C-214/89 (Comisión-España), por la que se estableció como principio, entre otras conclusiones, que no era admisible un sistema de recursos en el que se sometiera por regla general, la posibilidad de solicitar medidas cautelares en relación con las decisiones adoptadas por las entidades adjudicadoras a la necesidad de interponer previamente un recurso contra la decisión de ésta.

Por último, la sentencia del asunto C-444/06 que impone la obligación de que en la regulación de recursos se prevea un plazo de espera entre el momento en que se comunica a los licitadores la decisión de adjudicación y la celebración del contrato. Tal plazo de espera no tiene otra finalidad más que la de permitir que los licitadores cuyos derechos o intereses legítimos hayan podido resultar vulnerados por la decisión adjudicadora, puedan solicitar la adopción de medidas cautelares respecto de ella, así como interponer recurso para obtener, si procede, su revocación.

Fruto, entre otras, de estas circunstancias es la Directiva 2007/66/CE, de 11 de septiembre a que repetidamente nos venimos refiriendo y que, según la manifestación de su parte expositiva, viene a poner remedio a las debilidades apreciadas en la regulación hasta entonces vigente.

Entre tales debilidades, la Directiva trata de poner remedio a la inexistencia de un plazo de espera entre la adjudicación y la perfección del contrato, estableciendo, además, su duración y el dies a quo del cómputo, en función de cuál haya sido el medio a través del cual se haya producido la notificación del acuerdo de adjudicación.

Junto a este plazo de espera, la Directiva introduce una novedad de especial relevancia cual es la suspensión automática del procedimiento de contratación en el caso de que lo recurrido fuera el acto de adjudicación mismo. Su artículo 2.3 dispone que "cuando se someta a un órgano de primera instancia independiente del poder adjudicador un recurso referente a una decisión de adjudicación de un contrato, los Estados miembros garantizarán que el poder adjudicador no pueda celebrar el contrato hasta que el órgano que examine el recurso haya tomado una decisión sobre la solicitud de medidas provisionales o sobre el fondo del recurso". Esta consecuencia de la interposición del recurso, sin embargo, no afecta a aquellos casos en que el acto objeto de impugnación no fuera el de adjudicación. Así los dispone el artículo 2.4 cuando dice que en tales casos, "los procedimientos de recurso no tendrán necesariamente efectos suspensivos automáticos en los procedimientos de adjudicación de contratos a los que se refieran".

La consecuencia que deriva de esta suspensión, lleva necesariamente a considerar la conveniencia de establecer un procedimiento para la resolución del recurso que permita dictar ésta en un breve plazo. Y ello, porque de lo contrario, los efectos que sobre la actividad contractual de las diferentes administraciones, tendría la interposi30 ción del recurso podría resultar especialmente perjudicial. La exigencia de celeridad, 
tal como ya hemos tenido oportunidad de ver, comporta en nuestro derecho la ineludible necesidad de crear un órgano resolutorio especializado.

Finalmente la Directiva, introduce otra novedad de la que, igualmente, se deriva un especial refuerzo de los mecanismos jurídicos que permiten velar por el cumplimiento de la legislación comunitaria. A este fin, se crea un procedimiento a través del cual se puede pedir la ineficacia de los contratos ya celebrados cuando la celebración se haya hecho infringiendo las obligaciones de publicad, o sin respetar los plazos de espera y suspensión, de tal forma que los presuntos o efectivos licitadores hayan podido resultar privados por este hecho de la adjudicación de un contrato.

Sin embargo, por lo que aquí nos interesa, la modificación más relevante se refiere a la exigencia de que el recurso sea resuelto por un órgano independiente. Realmente la nueva Directiva no introduce ninguna modificación sustancial en la materia. La Directiva 89/665/CEE, ya exigía que la resolución se dictara por un órgano independiente que podía ser de carácter no jurisdiccional (artículo 2.6), pero al no ser exigible la suspensión automática del procedimiento, tal requisito quedaba suficientemente cumplido con la atribución de la competencia a los órganos de la Jurisdicción contencioso administrativa.

Por ello y tal como anteriormente analizamos, nuestro legislador había considerado que del texto de la citada directiva no se derivaba la necesidad de regular de modo específico el recurso en materia de contratación. La cuestión, sin embargo, varía sustancialmente a partir de la nueva regulación comunitaria. Al exigirse la suspensión del acto de adjudicación hasta que se resolviese acerca de las medidas cautelares a adoptar o sobre el fondo del recurso, resultaba inviable dicha atribución si se quería dar cumplimiento a la exigencia de eficacia al recurso, o no se quería perjudicar de manera irremediable la propia contratación pública.

Estas insuficiencias de nuestro sistema fueron puestas de manifiesto por la Comisión Europea en el Dictamen motivado de 8 de octubre de 2009, dirigido a España en relación al cumplimiento de la Sentencia del Tribunal de Justicia de las Comunidades Europeas de 3 de abril de 2008 en el asunto C-444/06. Dicha sentencia que se dicta con respecto de la Ley de Contratos de las Administraciones Públicas, declaró en su parte dispositiva que "el Reino de España ha incumplido las obligaciones que le incumben en virtud del artículo 2, apartado 1, letras a) y b), de la Directiva 89/665/CEE del Consejo, de 21 de diciembre de 1989, relativa a la coordinación de las disposiciones legales, reglamentarias y administrativas referentes a la aplicación de los procedimientos de recurso en materia de adjudicación de los contratos públicos de suministros y de obras (DO $1989 \mathrm{~L}$ 395, p.33), en su versión modificada por la Directiva 92/50/CEE del Consejo, de 18 de junio de 1992, al no prever un plazo obligatorio para que la entidad adjudicadora notifique la decisión de adjudicación de un contrato a todos los licitadores y al no prever un plazo de espera obligatorio entre la adjudicación de un contrato y su celebración". 
Como se aprecia, la Sentencia no se dicta en relación con la Ley 30/2007, de 30 de octubre sino con respecto a la de Contratos de las Administraciones Públicas que en la fecha de la Sentencia estaba a punto de perder vigor. Igualmente, la Directiva que se dice infringida es la 89/665/CEE, de 21 de diciembre de 1989, que en aquellos momentos ya había sido sustancialmente modificada por la 2007/66/CE, de 11 de diciembre.

En consecuencia, al menos en principio, no parece que, con base en esta Sentencia, la Comisión debiera haber entrado a analizar el grado de cumplimiento de la misma por la nueva Ley. En efecto, tal Ley aún no había entrado en vigor, aunque lo haría en breve, y, además los fundamentos legales de las Sentencia, las disposiciones de la Directiva 89/665/CEE, habían sido modificados de manera sustancial.

Sin embargo, la Comisión Europea, entendiendo que la Ley 30/2007, de 30 de octubre, había sido dictada en parte para recoger la doctrina del Tribunal de Justicia en cuanto a los dos puntos antes mencionados, consideró que podía analizar desde el punto de vista indicado la nueva Ley.

Acorde con ello, la Comisión Europea indica en su dictamen motivado que los servicios de la Comisión ya habían señalado en su carta de emplazamiento, las deficiencias por las que la vía de recurso arbitrada en el artículo 37 de la Ley 30/2007, de 30 de octubre, podría efectivamente ser de reducida eficacia: El hecho de que la suspensión automática prevista en el artículo 37 de la Ley de Contratos del Sector Público pudiera levantarse por el órgano de contratación, una vez notificada al demandante la resolución del recurso contra la decisión de adjudicación provisional y que esta resolución fuera, a su vez, susceptible de ser impugnada ante los Tribunales, si bien ese trámite no tenía el efecto de prorrogar la suspensión. Los servicios de la Comisión señalaban, además, que la eficacia del recurso podía sufrir merma, toda vez que el mismo no se interponía ante un órgano independiente, en una fase en la que aún podían corregirse las infracciones, sino ante el propio órgano de contratación.

Centrándonos en la cuestión objeto del presente artículo, la Comisión europea indica que el recurso especial del artículo 37 no puede ser calificado como un recurso eficaz puesto que no permite recurrir ante un órgano independiente del órgano de contratación.

"El órgano competente para resolver el recurso especial no satisface, a juicio de la Comisión, el requisito de independencia que necesariamente se deriva de la Directiva 89/665/CEE tal como la interpreta el Tribunal de Justicia, y concretamente el artículo 2 apartado 1, letras a) y b), de la misma".

A su juicio, "el objeto de la sentencia en el asunto C-444/06 se enmarca en el contexto de la necesidad de que los licitadores rechazados puedan interponer recursos eficaces contra la decisión de adjudicación del contrato y antes de su celebración, en una fase en 32 la que aún puedan corregirse las infracciones. En palabras del Tribunal, la Comisión alegó 
en dicho procedimiento que «la legislación nacional controvertida no se ajusta a la Directiva de recursos en la medida en que la combinación de determinadas disposiciones de la legislación impide que los licitadores rechazados interpongan eficazmente un recurso contra la decisión de adjudicación de un contrato antes de la propia celebración de éste» Como fue planteado por el Tribunal en la misma sentencia, 'De ello se desprende que, en determinados supuestos, no puede interponerse ningún recurso útil contra el acto de adjudicación antes de la ejecución misma del contrato, mientras que el objetivo de la Directiva sobre recursos consiste en garantizar que las decisiones ilícitas de los poderes adjudicadores puedan ser recurridas de manera eficaz y lo más rápidamente posible".

A la vista de los argumentos anteriores, la Comisión europea concluye que con la regulación prevista en el artículo 37 de la Ley de Contratos del Sector Publico en su redacción originaria los licitadores descartados no podrían interponer recurso directamente ante un órgano independiente pues debían interponer con carácter previo y obligatorio el recurso especial que debía resolver el propio órgano de contratación.

Ello supone que no se pueda "considerar que la introducción de una vía de recurso contra la decisión de adjudicación provisional antes de la celebración del contrato, bien ante el mismo órgano de contratación, bien ante un organismo al que ese órgano de contratación está adscrito, constituya un procedimiento de recurso adecuado y eficaz en el sentido del artículo 2, apartado 1, letras a) y b), de la Directiva 89/665/ CEE, tal como interpretó el Tribunal de Justicia en su sentencia en el asunto C-444/06... En consecuencia, aceptar como plenamente conforme a la sentencia en el asunto C-444/o6 que en el plazo de espera obligatorio entre la adjudicación del contrato y su celebración, destinado a permitir que los licitadores excluidos interpongan un recurso eficaz contra la decisión de adjudicación, sólo sea posible impugnar la adjudicación ante el propio órgano de contratación privaría de eficacia al núcleo mismo de la citada sentencia".

Finalmente, la Comisión aclara que el dictamen no critica la existencia de un recurso administrativo especial para la impugnación de la decisión de adjudicación previo a la vía jurisdiccional. Tampoco que la sentencia en el asunto C-444/06 exija que la decisión de adjudicación deba poder impugnarse ante un órgano jurisdiccional. Simplemente pone de manifiesto que, tal como resulta de la Sentencia citada la Ley 30/2007, de 30 de octubre no prevé un período de espera obligatorio entre la adjudicación de un contrato y su celebración que permita a los licitadores rechazados interponer recursos eficaces en una fase en la que aún puedan corregirse las infracciones. A fin de garantizar la eficacia de un procedimiento de recurso, es preciso que los licitadores excluidos tengan la posibilidad de recurrir ante un órgano independiente del órgano de contratación, de forma que la decisión de adjudicación pueda impugnarse. Y ello porque "sólo un órgano independiente es capaz de garantizar una protección jurídica plena y eficaz frente a las decisiones de los órganos de contratación".

Hemos querido detenernos de forma extensa en el análisis de este dictamen motivado para poder calibrar hasta qué punto el legislador español se vio compelido, 
al redactar la Ley 34/2010, de 5 de agosto a tener en consideración condicionantes que evitaran un nuevo procedimiento de infracción contra el Reino de España.

\section{ESTRUCTURA}

\section{Funcionamiento}

Sentado esto, corresponde ahora entrar en el análisis de la estructura y funcionamiento del Tribunal Administrativo Central de Recursos Contractuales.

La regulación de los aspectos fundamentales del Tribunal, tanto en cuanto a estructura, como respecto de su funcionamiento se contienen en el artículo 41, de la Ley de Contratos del Sector Público, introducido por la Ley 34/2010, de 5 de agosto de Modificación de las Leyes 30/2007, de 30-10-2007, de Contratos del Sector Público, 31/2007, de 30-10-2007, sobre procedimientos de contratación en los sectores del agua, la energía, los transportes y los servicios postales, y 29/1998, de 13-7-1998, reguladora de la Jurisdicción Contencioso-Administrativa para adaptación a la normativa comunitaria de las dos primeras.

Para nuestro estudio interesan básicamente el apartado uno y los párrafos segundo y tercero del apartado dos.

El primero de ellos regula en primer lugar la composición del Tribunal, "se crea el Tribunal Administrativo Central de Recursos Contractuales que estará adscrito al Ministerio de Economía y Hacienda y compuesto por un Presidente y un mínimo de dos vocales. Reglamentariamente podrá incrementarse el número de vocales que hayan de integrar el Tribunal cuando el volumen de asuntos sometidos a su conocimiento lo aconseje".

No prevé la Ley en qué condiciones se debe considerar que el volumen de asuntos sometidos a su conocimiento deberá motivar el incremento del número de los vocales. Evidentemente, es ésta una cuestión que sólo a la luz de la experiencia acumulada deberá resolverse. Sólo cuando el análisis del incremento periódico de los asuntos ponga de manifiesto una tendencia a alcanzar niveles de saturación derivados de la propia experiencia del Tribunal, podrá llegarse a la conclusión de que el número de los vocales debe ser incrementado. Lo que sí es importante, a este respecto, es que el aumento de los mismos sea un instrumento preventivo y no correctivo de una situación de disfuncionalidad del Tribunal. Es decir que el número de vocales se incremente para evitar la saturación y no para corregir la saturación ya producida. No sólo el buen funcionamiento del propio Tribunal sino también la necesidad de no entorpecer la marcha de los procedimientos de contratación y de garantizar la eficacia del recurso, lo exigen.

La designación de los miembros del Tribunal exige, un examen previo de lo dis34 puesto al respecto en la Directiva 2007/66/CE de 11 de diciembre. Su artículo 2.9 dice 
que "El nombramiento de los miembros de esta instancia independiente y la terminación de su mandato estarán sujetos a las mismas condiciones aplicables a los jueces en lo relativo a la autoridad responsable de su nombramiento, la duración de su mandato y su revocabilidad. Como mínimo, el presidente de esta instancia independiente deberá poseer las mismas cualificaciones jurídicas y profesionales que un juez".

El precepto anterior contiene básicamente dos elementos de regulación. El primero de ellos hace referencia a los requisitos para el nombramiento y terminación del mandato de los miembros del órgano independiente encargado de resolver los recursos. El segundo se refiere a las condiciones de carácter jurídico y profesional que deben reunir.

En cuanto al primero de los elementos citados, el precepto comunitario se limita a indicar que deberán ser los mismos a que estarían sujetos el nombramiento y terminación del mandato de los jueces en cuanto a

a) Autoridad responsable del nombramiento,

b) Duración del mandato

c) Revocabilidad del nombramiento.

Los tres requisitos requieren en análisis detenido. En primer lugar, se trata de establecer si existe coincidencia entre los requisitos exigidos a los efectos indicados para la carrera judicial y los exigibles respecto de la Autoridad responsable del nombramiento, duración del mandato y revocabilidad en relación con los miembros del Tribunal porque sólo así podría considerarse que la Ley de Contratos del Sector Público, tras la reforma de la Ley 34/2020, de 5 de agosto, ha dado pleno cumplimiento a lo dispuesto en la Directiva 2007/66/CE que tantas veces hemos mencionado.

Al respecto, esta última Ley en su artículo 41.1, párrafo seis, dispone que "la designación del Presidente y los Vocales de este Tribunal se realizará por el Consejo de Ministros a propuesta conjunta de los Ministros de Economía y Hacienda y de Justicia".

A tenor de lo dispuesto en el artículo 316.2 de la Ley Orgánica 6/1985, de 1 de julio, Orgánica del Poder Judicial, el nombramiento de los Magistrados se hará mediante Real Decreto, a propuesta del Consejo General del Poder Judicial. En realidad existen diferencias entre el nombramiento por el Consejo de Ministros a propuesta de dos de ellos y el nombramiento hecho por Real Decreto que debe ser firmado por Su Majestad el Rey con el refrendo del proponente. Sin embargo, tratándose de cargos puramente administrativos parece que el legislador ha entendido que bastaba con atribuir la competencia para el nombramiento al Consejo de Ministros como órgano superior de la estructura de la Administración general del Estado, sustituyendo propuesta del Consejo General del Poder Judicial, que no tenía justificación alguna tratándose de cargos no judiciales, por la propuesta conjunta de los Ministros de Econo- 
mía y Hacienda, competente por razón de la materia, y el de Justicia como órgano responsable de las cuestiones que afectan más íntimamente al derecho.

El segundo requisito exigido por la Directiva se refiere a la duración del cargo. Al respecto, el artículo 41.1, en su párrafo 8 establece: “La duración del nombramiento efectuado de conformidad con este apartado será de seis años y no podrá prorrogarse".

El parangón con la regulación que de esta materia hace la Ley Orgánica del Poder Judicial es imposible. En la carrera judicial la categoría de Juez o de Magistrado se adquiere con carácter vitalicio. De igual forma los cargos que a lo largo de su carrera puedan ostentar Jueces y Magistrados, por regla general, no tienen plazo de caducidad, o cuando lo tienen es porque dichos cargos no tienen contenido propiamente jurisdiccional. En consecuencia, la Ley de Contratos del Sector Público, en este punto se aparta de la exigencia comunitaria literalmente entendida.

No obstante, entendemos que la interpretación del precepto no debe ser desfavorable, toda vez que carecen de entronque con el sistema estructural y funcionarial español, como en general con el de cualquier Administración moderna, la creación de puestos y cargos de carácter vitalicio. La misma función de independencia puede conseguirse estableciendo la duración del cargo y desterrando la posibilidad de reelección. Desde este punto de vista, a nuestro entender, la norma citada da plena satisfacción a la exigencia de la Directiva.

Por último, se exige que también se observen la normas relativas a la inamovilidad de los jueces, al indicar que estará sujeta a las mismas condiciones aplicables a los Jueces, la revocabilidad del mandato. En este sentido, el Texto Refundido de la Ley de Contratos del Sector Público, en su artículo 41.1, párrafo 7, dispone: "Los designados tendrán carácter independiente e inamovible, y no podrán ser removidos de sus puestos sino por las causas siguientes:

a) Por expiración de su mandato.

b) Por renuncia aceptada por el Gobierno.

c) Por pérdida de la nacionalidad española.

d) Por incumplimiento grave de sus obligaciones.

e) Por condena a pena privativa de libertad o de inhabilitación absoluta o especial para empleo o cargo público por razón de delito.

f) Por incapacidad sobrevenida para el ejercicio de su función.

La remoción por las causas previstas en las letras c), d), e) y f) se acordará por el 36 Gobierno previo expediente" 
Este precepto, sí guarda una semejanza prácticamente absoluta con la norma equivalente de la Ley Orgánica del Poder Judicial, el artículo 379.

Todos estos preceptos vienen a articular la exigencia de que los designados para integrar el Tribunal tengan carácter independiente e inamovible tal como exige el artículo 41.1, exigencia que constituye el modo de garantizar que el Tribunal actúe con plena independencia funcional en el ejercicio de sus competencias.

Analizados los requisitos relacionados con el nombramiento de los miembros del Tribunal en los aspectos mencionados por el artículo transcrito de la Directiva 2007/66/CE, corresponde ahora examinar cuáles son los exigidos con respecto de cada uno de los miembros para que puedan ser designados.

La Directiva, a este respecto, contiene tan solo una norma del siguiente tenor: "Como mínimo, el presidente de esta instancia independiente deberá poseer las mismas cualificaciones jurídicas y profesionales que un juez". Sin embargo, los artículos del Derecho interno que regulan las condiciones exigibles para acceder a la carrera judicial a través de la categoría de Juez, no pueden ser de aplicación porque ello supondría superar las correspondientes oposiciones y posteriormente realizar el curso en la Escuela Judicial (art. 301.3 de la Ley Orgánica del Poder Judicial).

El precepto de la Directiva no exige ser Juez, sino que se cumplan determinados requisitos formales para la designación de los miembros del Tribunal. Por ello resulta asumible, lo dispuesto en la Ley Orgánica citada con respecto de los requisitos exigibles para el ingreso en la carrera judicial por la categoría de Magistrado. La Ley $34 / 2010$, de 5 de agosto, a este respecto ha considerado conveniente exigir una cualificación de la máxima categoría.

Ante todo, del texto anterior debemos deducir que, sensu contrario, el legislador comunitario considera preciso establecer requisitos en cuanto a la condición como jurista más que en la persona del Presidente.

Veamos cuáles son esos requisitos. La directiva se limita a decir que deberá poseer las mismas cualificaciones jurídicas y profesionales que un Juez. El término cualificaciones no es habitual en la literatura jurídica para referirse a esta materia, por lo que habría sido más precisa su traducción como "requisitos" o "exigencias" jurídicas o profesionales.

Tampoco se entiende muy bien qué son cualificaciones o exigencias jurídicas, pues, en general, cualquier requisito exigible para el ejercicio de una determinada función, debe tener la consideración de requisito de carácter jurídico, incluidos los requisitos de carácter profesional. Todos ellos son condiciones de validez del acto administrativo del nombramiento y, por consiguiente, no cabe dudar de su carácter de requisitos jurídicos. 
Como se ha dicho anteriormente, para la determinación de los requisitos que debe reunir el Presidente del Tribunal, debemos considerar todas aquellas exigencias previstas en la Ley para poder ser Juez o Magistrado, que no tengan la consideración de requisitos de carácter profesional.

En tal sentido el artículo 302 de la Ley Orgánica del Poder Judicial, dispone que para acceder a la carrera judicial "se requiere ser español, mayor de edad y licenciado en Derecho, así como no estar incurso en alguna de las causas de incapacidad que establece la Ley". Estos requisitos, salvo el referente a la titulación en Derecho, coinciden básicamente con los exigidos para ser funcionario en el artículo 56 de la Ley 7/2007, de 12 de abril, Estatuto básico del empleado público, en consecuencia deben considerarse cumplimentados con la exigencia al Presidente de pertenecer a un Cuerpo de funcionarios. Además, el requisito de ser licenciado en Derecho se cumple, al exigir que el Cuerpo de procedencia del Presidente sea alguno de aquellos en que para ingresar se exige el titulo de licenciado o grado en Derecho.

Consecuente con ello establece la necesidad de que el Presidente del Tribunal Central cumpla los requisitos exigidos por el artículo 345 para poder ser designado magistrado del Tribunal Supremo por el turno de juristas de prestigio, es decir cumplir los requisitos generales para pertenecer a la magistratura, haber ejercido en su cuerpo por tiempo superior a quince años y acreditar especialización en la rama del derecho administrativo con especial dedicación al ámbito de la contratación pública. Aparte del propósito de la Ley en relación con el cumplimiento de los requisitos exigidos por la Directiva 2007/66/CE, es obvio que además pretende exigir el máximo nivel posible para ser Presidente del Tribunal.

Podrían plantearse dos cuestiones relativas a si no hubiera sido posible dar cumplimiento a la Directiva sin necesidad de acudir a la exigencia de requisitos tan severos para poder ser Presidente del Tribunal Central. Al respecto resulta obvio que la Ley podría haber optado por exigir simplemente los requisitos establecidos para acceder a la condición de Magistrado por el denominado cuarto turno, es decir ser jurista con al menos diez años de ejercicio. Sin embargo, el legislador ha optado por esta exigencia máxima para el Presidente del Tribunal Central, probablemente para poder establecer para los Presidentes de los Tribunales Territoriales el siguiente nivel de exigencia establecido en la Ley.

Otra cuestión a debatir se refiere a si no hubiera sido suficiente para dar cumplimiento a la norma comunitaria la exigencia general establecida en el artículo 302 de la Ley orgánica del Poder Judicial, unida a la exigencia de pertenecer a un cuerpo de funcionarios. A nuestro juicio de haberse inclinado la Ley por esta posibilidad, difícilmente se podría considerar que habría dado cumplimiento a los requisitos exigidos para ser juez tal como lo exige la Directiva. En nuestro sistema judicial para ser juez no basta con ser español, mayor de edad y licenciado en derecho, sino que además hay que superar las oposiciones y el curso en la carrera judicial, o bien cumplir los requisitos exigidos para 38 ingresar por el cuarto turno o, finalmente, para ser Magistrado del Tribunal Supremo. 
En cuanto a los vocales, aunque la Directiva guarda silencio, el legislador español ha considerado oportuno exigir los mismos requisitos que al Presidente, salvo el relativo a la exigencia de la titulación en Derecho para el ingreso en el Cuerpo de procedencia.

\section{CONVENIOS}

\section{Su naturaleza jurídica}

Una de las novedades de la reforma operada por la Ley 34/2010 en la Ley de Contratos del Sector Público es el régimen de atribución de competencia al Tribunal, a través de convenios, por las Comunidades Autónomas.

El texto después de la reforma queda redactado de la siguiente manera: "Podrán las Comunidades Autónomas, asimismo, atribuir la competencia para la resolución de los recursos al Tribunal especial creado en el apartado 1 de este artículo. A tal efecto, deberán celebrar el correspondiente convenio con la Administración General del Estado, en el que se estipulen las condiciones en que la Comunidad sufragará los gastos derivados de esta asunción de competencias.

Las Ciudades Autónomas de Ceuta y Melilla podrán designar sus propios órganos independientes ajustándose a los requisitos establecidos en este apartado para los órganos de las Comunidades Autónomas, o bien atribuir la competencia al Tribunal Administrativo Central de Recursos Contractuales celebrando al efecto un convenio en los términos previstos en el párrafo anterior" (art. 41.3 TRLCSP).

Ante todo hay que poner de manifiesto que esta atribución, a pesar de la mención que en ella se hace a los convenios, no es una acto bilateral entre el Estado y las CCAA sino que lo que la ley hace es atribuir a estas la decisión exclusiva de atribuir esta competencia al Tribunal sin que por el Estado haya posibilidad de oposición.

Esto dicho, el convenio no tiene más finalidad que la de regular las consecuencias de esa atribución y las condiciones en que debe llevarse a la práctica.

Surge así la cuestión de cómo debe calificarse jurídicamente esta atribución. Dada la dicción literal del artículo objeto de estudio, podría pensarse, a primera vista, que nos encontramos ante una delegación de competencias (piénsese que el precepto habla de atribución de competencia para la resolución de los recursos). Ahora bien, dicha interpretación sería contraria al artículo 13 de la LRJAPPAC, que no permite la delegación de competencias entre órganos de distintas Administraciones; parece, por tanto, mucho más razonable pensar que nos encontramos ante una encomienda de gestión de las previstas en el artículo 15 de la Ley de Procedimiento.

El citado artículo dispone lo siguiente: 
"1. La realización de actividades de carácter material, técnico o de servicios de la competencia de los órganos administrativos o de las Entidades de Derecho público podrá ser encomendada a otros órganos o Entidades de la misma o de distinta Administración, por razones de eficacia o cuando no se posean los medios técnicos idóneos para su desempeño.

2. La encomienda de gestión no supone cesión de titularidad de la competencia ni de los elementos sustantivos de su ejercicio, siendo responsabilidad del órgano o Entidad encomendante dictar cuantos actos o resoluciones de carácter jurídico den soporte o en los que se integre la concreta actividad material objeto de encomienda.

3. La encomienda de gestión entre órganos administrativos o Entidades de derecho público pertenecientes a la misma Administración deberá formalizarse en los términos que establezca su normativa propia y, en su defecto, por acuerdo expreso de los órganos o Entidades intervinientes. En todo caso el instrumento de formalización de la encomienda de gestión y su resolución deberá ser publicado, para su eficacia en el Diario Oficial correspondiente.

Cada Administración podrá regular los requisitos necesarios para la validez de tales acuerdos que incluirán, al menos, expresa mención de la actividad o actividades a las que afecten, el plazo de vigencia y la naturaleza y alcance de la gestión encomendada.

4. Cuando la encomienda de gestión se realice entre órganos y Entidades de distintas Administraciones se formalizará mediante firma del correspondiente convenio entre ellas, salvo en el supuesto de la gestión ordinaria de los servicios de las Comunidades Autónomas por las Diputaciones Provinciales o en su caso Cabildos o Consejos insulares, que se regirá por la legislación de Régimen Local.

5. El régimen jurídico de la encomienda de gestión que se regula en este artículo no será de aplicación cuando la realización de las actividades enumeradas en el apartado primero haya de recaer sobre personas físicas o jurídicas sujetas a Derecho privado, ajustándose entonces, en lo que proceda, a la legislación correspondiente de contratos del Estado, sin que puedan encomendarse a personas o Entidades de esta naturaleza actividades que, según la legislación vigente, hayan de realizarse con sujeción al Derecho administrativo".

A la vista del artículo trascrito, es evidente que la posibilidad establecida en el artículo 41.2 de la Ley de Contratos encaja perfectamente en la figura de la encomienda de gestión prevista en el apartado primero, pero en el bien entendido caso de que, en el supuesto del Tribunal, se trata de una encomienda que no puede rechazarse. De acuerdo con ello, desde el punto de vista de las Comunidades Autónomas, la encomienda no presentaría peculiaridades, mientras que, en el caso del Tribunal, se trataría de una especie de encomienda de gestión ex lege que, una vez propuesta, no puede rechazarse.

Una de las principales cuestiones que plantea el Convenio, es el régimen de recursos judiciales. A pesar de que, con carácter general, la competencia para conocer 40 de los recursos contencioso-administrativos frente a las resoluciones del Tribunal, se 
atribuye a la Audiencia Nacional (artículo 11.1 f) de la Ley 29/1998 de la Jurisdicción Contencioso-Administrativa, en la reforma operada por la Ley 34/2010 de 5 de agosto), competencia que viene determinada por el carácter de órgano central del Tribunal y su rango, lógicamente, en el caso de que se resuelvan recursos frente a resoluciones de las Comunidades Autónomas, la situación no es igual. La solución por la que ha optado el legislador, en este caso, es determinar la competencia judicial en función del origen de la resolución recurrida ante el Tribunal, de tal forma que, en el caso de que la resolución recurrida provenga de una Comunidad Autónoma, se atribuye la competencia al Tribunal Superior de Justicia territorialmente competente (artículo 10.1 k) de la Ley 29/1998 en la reforma operada por la Ley 34/2010 de 5 de agosto).

Finalmente, esta atribución de competencias debe quedar regulada mediante el oportuno convenio. Respecto de su contenido, la Ley solamente se refiere a las condiciones en que la Comunidad sufragará los gastos derivados de esta asunción de competencias. Evidentemente, no puede ser éste el único contenido del Convenio. Aunque no existe un desarrollo reglamentario que permita el apoyo normativo para su clausulado, se puede determinar sin dificultad el mismo. Así, los convenios que se celebren, deberán establecer el régimen jurídico, los ámbitos subjetivo y objetivo de aplicación, la forma de articular la relaciones derivadas de la aplicación del Convenio, la preceptiva publicación del mismo, la fecha de entrada en vigor y duración, así como el régimen transitorio a aplicar a los procedimientos ya en curso en el momento de la entrada en vigor y de la extinción del Convenio. 
